\title{
MOTIVO DA PROCURA DO CENTRO OBSTÉTRICO DO HOSPITAL SÃO JOSÉ POR GESTANTES DO MUNICÍPIO DE CRICIÚMA
}

\section{Gabriela Vefago Nunes}

Enfermeira. Universidade do Extremo Sul Catarinense, Brasil.

Érica Berckenbrock Brunel

Enfermeira. Universidade do Extremo Sul Catarinense, Brasil.

\section{Francielle Lazzarin de Freitas Gava}

Enfermeira. Mestrado Multiprofissional em Saúde Coletiva. Universidade do Extremo Sul Catarinense. UNESC. Professor Titular da Universidade do Extremo Sul Catarinense.

\section{Cecília Marly Spiazzi dos Santos}

Enfermeira. Mestrado em Ciências da Saúde. Universidade do Extremo Sul Catarinense. UNESC. Professor Titular da Universidade do Extremo Sul Catarinense.

\section{Mônica Dal Pont Bonfanti}

Enfermeira. Especialização em Residência Multiprofissional em Saúde Coletiva pela Universidade do Extremo Sul Catarinense. Residente do Ministério da Saúde.

\section{Ioná Vieira Bez Birolo}

Enfermeira. Mestrado em Enfermagem pela Universidade Federal de Santa Catarina. Professor Mestre Categoria II da Universidade do Extremo Sul Catarinense.

Autor correspondente

Gabriela Vefago Nunes

E-mail: gabyvefago@hotmail.com
RESUMO: O presente estudo objetiva identificar os motivos que levam as gestantes a procurar o centro obstétrico do hospital São José do município de Criciúma-SC. Trata-se de uma pesquisa de abordagem quantitativa transversal e descritiva. A pesquisa aconteceu com 353 gestantes/parturientes, no período de novembro de 2016 a março de 2017, onde se aplicou entrevista semiestruturada elaborada pelo comitê de mortalidade materno-infantil de Criciúma-SC juntamente com as pesquisadoras. A análise dos dados foi realizada a partir dos dados coletados, atendendo critérios estatísticos. Os resultados mostraram que os principais motivos que levaram as gestantes a procurar o centro obstétrico foram dor (49,9\%), contração (15\%), sangramento (13\%), perda de líquido amniótico $(12,7 \%)$, pressão alta $(9,6)$ e expectativa de parturir $(9,1 \%)$. A maioria das participantes não procurou a Unidade Básica de Saúde antes de ir ao centro obstétrico, e, as que procuraram consideraram o atendimento como não resolutivo. Sugerimos que os profissionais da equipe de saúde busquem ações para aumentar o vínculo com as gestantes/parturientes durante todo o processo gestacional.

PALAVRAS-CHAVE: Pré-natal; Gestante; Unidade Básica de Saúde; Centro obstétrico; Enfermagem.

\section{REASONS BY PREGNANT WOMEN FOR ATTENDING THE OBSTETRIC CENTER OF THE HOSPITAL SÃO JOSÉ, CRICIÚMA, BRAZIL}

ABSTRACT: The reasons why pregnant women go to the obstetric center of the Hospital São José in Criciúma, Brazil, are identified by a transversal, descriptive and quantitative research. Current investigation focused on 353 pregnant females between November 2016 and March 2017 , to whom a half-structured interview, prepared by the motherchild mortality committee of Criciúma SC Brazil and by researchers, was applied. Data analysis was prepared from information collected, based on statistical criteria. Results show that the main motives were pain (49.9\%), contraction (15\%), bleeding (13\%), loss of the amniotic fluid (12.7\%), high pressure (9.6) and expectations in giving birth (9.1\%). Most participants did not attend the Basic Health Unit prior to going to the obstetric center. Females who went to the BHU alleged attendance failed to solve anything. Health teams are recommended to increase bonding with pregnant women during the entire pregnancy period.

KEY WORDS: Pre-natal exam; Pregnant female; Basic Health Unit; Obstetric center; Nursing. 


\section{INTRODUÇÃO}

Dar à luz de forma natural a um bebê saudável é uma das experiências mais intensas da vida de uma mulher. A qualidade da atenção prestada durante a gravidez, o parto e após o nascimento podem ter efeitos marcantes sobre a vida da mãe e do bebê. Uma assistência humanizada ao parto e ao nascimento se fundamenta no respeito, na dignidade e autonomia das mulheres e das crianças ${ }^{1}$.

O governo federal lançou em 2011 a Rede Cegonha, uma estratégia para proporcionar às mulheres saúde, qualidade de vida e bem-estar durante a gestação, parto, pós-parto e o desenvolvimento da criança até os dois primeiros anos de vida. Esta estratégia tem o objetivo de reduzir a mortalidade materna e infantil e garantir os direitos sexuais e reprodutivos de mulheres, homens, jovens e adolescentes. A proposta qualifica os serviços ofertados pelo SUS no planejamento familiar, na confirmação da gravidez, no pré-natal, no parto e no puerpério ${ }^{1}$.

As intercorrências estão associadas, mesmo que de forma indireta, a qualidade da atenção dispensada à mulher durante a gestação, seja ela relacionada à educação, promoção, prevenção, diagnóstico precoce ou tratamento. Ou seja, quanto melhor o acesso e a qualidade do atendimento, menores as taxas de internação por complicações obstétricas ${ }^{2}$.

A UBS é o ponto de atenção estratégico para melhor acolher as necessidades da gestante e deve ser a porta de entrada preferencial da mesma no sistema de saúde, inclusive proporcionando um acompanhamento longitudinal e continuado, principalmente durante a gravidez. É necessário identificar os fatores de risco gestacional o mais precocemente possível com o objetivo de reduzir a morbimortalidade materno-infantil e ampliar o acesso com qualidade 3 .

As mulheres dão preferência ao serviço especializado, por sua capacidade e agilidade de investigação e intervenção nos problemas gestacionais. Porém procuram manter o contato sistemático com a estratégia de saúde da família e os serviços especializados, pela importância dada também ao vínculo construído com os profissionais da estratégia de saúde da família: ${ }^{4: 00}$.
A motivação para esta pesquisa surgiu nas reuniões do Comitê de Mortalidade Materna e Infantil (CMMI) do município de Criciúma. A partir da inquietação sobre o tema, discutido incansavelmente no CMMI, como quais os motivos que levam as gestantes a procurar os serviços oferecidos por um centro obstétrico e o perfil epidemiológico destas, foi realizado este estudo para encontrar algumas respostas.

Sendo que estes resultados podem ser usados como forma de subsidiar ações para conscientizar os profissionais sobre a importância da atenção de qualidade no ciclo gravídico puerperal com realização do pré-natal e criação de vínculos com a mulher, fazendo com que a gestante procure a UBS para solucionar seus problemas, receber as orientações pertinentes e, se necessário, ser encaminhada a outro setor/instituição.

O resultado deste estudo pode elucidar fatores para fortalecer uma rede integralizada de atendimento à mulher com objetivo de acompanhá-la na atenção básica por meio do pré-natal, conhecendo suas características pessoais e anseios, visando à diminuição de possíveis complicações e intercorrência na gestação, no parto e puerpério.

Assim, é importante conhecer o perfil dessas pacientes e os motivos que as levam a procurar o hospital, assim como suas expectativas e satisfação em relação ao parto, para refletir e discutir sobre a realidade da atenção prestada a essas gestantes/parturientes e planejar meios para que a Rede Cegonha aconteça de forma efetiva no município. A partir destas reflexões tem-se como problema de pesquisa: Qual o motivo da procura do centro obstétrico do Hospital São José (HSJ) por gestantes do município de Criciúma - SC?

Buscando identificar os motivos que levam as gestantes a procurar o centro obstétrico, elencaram-se as hipóteses: a maioria das gestantes procura o centro obstétrico por desconforto relacionado à gestação, tais como sangramento, perda de líquido amniótico, dor, queda e falso trabalho de parto; a maioria das gestantes procura o centro obstétrico por motivos que poderiam ser resolvidos na atenção básica em saúde; a maioria das gestantes que procuram o centro obstétrico tem vínculo empregatício, são primigestas, estão na faixa etária entre 16 e 35 anos com ensino médio incompleto. 
Diante das reflexões sobre a temática tem-se como objetivo da pesquisa identificar os motivos da procura do centro obstétrico, por gestantes e parturientes do HSJ do município de Criciúma (SC).

\section{METODOLOGIA}

A abordagem da pesquisa caracterizou-se como quantitativa, do tipo descritiva e transversal.

A pesquisa foi realizada no centro obstétrico do HSJ, Criciúma - SC. O HSJ teve início em 24 de janeiro de 1932. O centro obstétrico onde foi realizada a pesquisa faz parte do Hospital São José desde o início do hospital, atende em média de 900 a 1.100 gestantes mensalmente, que precisam de atendimento, quando estão em trabalho de parto ou vem em busca de tratamento para intercorrências gravídicas. São realizados, em média, 200 partos por mês. Possui quatro leitos de internação, duas salas de parto, uma para cesáreas e outra para partos vaginais 5 .

Os sujeitos do estudo foram todas as gestantes/ parturientes que compareceram ao centro obstétrico do HSJ de 07 de novembro a 07 de dezembro de 2016 de segunda a sexta feira, das $17 \mathrm{~h} 30 \mathrm{~min}$ às $22 \mathrm{~h} 30 \mathrm{~min}$. E no período de $1^{\circ}$ de fevereiro a 02 de março de 2017 , de segunda a sexta feira, das $08 \mathrm{~h} 00 \mathrm{~min}$ às $12 \mathrm{~h} 00 \mathrm{~min}$ e das $13 \mathrm{~h} 00 \mathrm{~min}$ às $17 \mathrm{~h} 00 \mathrm{~min}$. Foram entrevistadas 353 gestantes/parturientes nos dois períodos.

Foi aplicada uma entrevista semiestruturada, elaborada no Comitê de Mortalidade Materna e Infantil de Criciúma, sobre o perfil epidemiológico, demográfico e obstétrico das gestantes, e, sobre a resolutividade da atenção na UBS na perspectiva das gestantes e parturientes que procuraram o centro obstétrico durante o período da pesquisa, além das informações sobre possíveis atendimentos que antecederam a chegada ao hospital, posteriormente, organizaram-se as temáticas norteadoras.

Utilizou-se como critérios de inclusão: gestantes, parturientes, que estavam em condições físicas e cognitivas para responder a pesquisa; gestantes e parturientes maiores de 16 anos mediante assinatura do responsável; gestantes e parturientes internadas ou em observação no centro obstétrico.

$\mathrm{Na}$ fase de análise de dados, as informações fo- ram quantificadas através do Microsoft Office Excel. Para a realização da pesquisa os sujeitos do estudo assinaram o termo de consentimento livre e esclarecido, sendo que este assegura o sigilo da identidade dos participantes. $\mathrm{O}$ termo segue as exigências formais contidas na resolução 510/16, do Conselho Nacional de Saúde.

A pesquisa em seres humanos deverá sempre tratá-lo com dignidade, respeito e defendê-lo em sua vulnerabilidade. Segundo as diretrizes e normas regulamentadoras de pesquisas envolvendo seres humanos, os participantes devem ser esclarecidos sobre a natureza da pesquisa, seus objetivos, métodos, benefícios previstos, potenciais riscos e o incômodo que esta possa lhes acarretar, na medida de sua compreensão e respeitados em suas singularidades ${ }^{6}$.

A resolução incorpora referenciais da bioética: autonomia, não maleficência, beneficência, justiça e equidade e visa assegurar os direitos e deveres que dizem respeito à comunidade científica, aos sujeitos da pesquisa $\mathrm{e}$ do Estado ${ }^{6}$.

Dentre os aspectos éticos, o consentimento livre e esclarecido prevê a anuência do sujeito da pesquisa após a explicação completa sobre a natureza da mesma, seus objetivos, métodos, benefícios previstos e potenciais riscos que possam acarretar, formulada em termo de consentimento, autorizando sua participação na pesquisa ${ }^{6}$.

Para preservar o sigilo decorrente da aplicação da entrevista e de acordo com as diretrizes e normas regulamentadoras da resolução 510/16 que envolvem pesquisa com seres humanos, as participantes da pesquisa foram identificadas pela letra GE (gestante) e PA (parturiente) com número de ordem como, por exemplo, GE1, GE2, GE3 e assim sucessivamente.

Após a aprovação da pesquisa pelo Comitê de Ética em Pesquisa da Universidade do Extremo Sul Catarinense (Parecer $n^{0} 1.348 .539$ ), iniciou-se a coleta de dados. Durante o período da pesquisa foram abordadas para a entrevista todas as gestantes/parturientes que chegavam ao centro obstétrico.

\section{RESULTADOS}

Das participantes do estudo 94,6\% (334) eram gestantes e 5,4\% (19) parturientes. Relacionado à idade gestacional no momento da pesquisa $166(47,0 \%)$ das 
participantes estavam no nono mês de gestacional. A maioria das participantes do estudo, $326(92,4 \%)$, reside com o pai do bebê e 38 participantes $(10,8 \%)$ relataram receber algum tipo de auxílio ou pensão.

Relacionado ao histórico gestacional, a predominância foi de participantes que estavam na primeira gestação 124 (35,1\%), não tiveram nenhum parto 142 participantes $(40,2 \%)$ e relataram não ter nenhum aborto 282 participantes $(79,9 \%)$.

A faixa etária predominante das participantes do estudo foi de 21 a 30 anos de idade com 163 participantes $(46,2 \%)$, o município com mais participantes que procuraram o centro obstétrico durante a pesquisa foi Criciúma com 252 participantes $(71,4 \%)$, e em relação à escolaridade a maioria, 136 (38,5\%), tinha o ensino médio completo.

Tabela 1. Perfil sociodemográfico das participantes do estudo

\begin{tabular}{lc}
\hline & $\mathbf{N}=353(\%)$ \\
\hline Faixa etária & \\
16 a 20 anos & $163(46,1 \%)$ \\
21 a 30 anos & $92(26,1 \%)$ \\
31 a 40 anos & $6(1,7 \%)$ \\
41 a 50 anos & \\
\hline Município & $252(71,4 \%)$ \\
\hline Criciúma & $36(10,2 \%)$ \\
Forquilhinha & $20(5,7 \%)$ \\
Içara & $9(2,5 \%)$ \\
Siderópolis & $7(2,0 \%)$ \\
Morro da Fumaça & $7(2,0 \%)$ \\
Urussanga & $6(1,7 \%)$ \\
Araranguá & $5(1,4 \%)$ \\
Cocal do Sul & $4(1,1 \%)$ \\
Balneário Rincão & $4(1,1 \%)$ \\
Nova Veneza & $1(0,3 \%)$ \\
Lauro Muller & $1(0,3 \%)$ \\
Orleans & $1(0,3 \%)$ \\
Ermo & $36(10,2 \%)$ \\
\hline Escolaridade & $35(9,9 \%)$ \\
\hline Fundamental incompleto & $89(25,2 \%)$ \\
Fundamental completo & $136(38,5 \%)$ \\
Médio incompleto & $23(6,5 \%)$ \\
Médio completo & $27(7,6 \%)$ \\
Superior incompleto & $7(2,0 \%)$ \\
Superior completo &
\end{tabular}

Fonte: Dados da pesquisa, 2017.
De acordo com o atendimento da gestante na UBS, $228(64,6 \%)$ das participantes não procuraram a UBS antes de vir ao centro obstétrico. Das participantes que foram a UBS onde realizam o acompanhamento prénatal antes de vir ao centro obstétrico, 65 (18,4\%) foram atendidas pelo médico (a), e 18 (5,1\%) pelo enfermeiro (a). Sobre a resolução do atendimento, 78 participantes $(22,1 \%)$ não consideraram o atendimento resolutivo. O motivo que levou a procura do centro obstétrico após o atendimento na UBS apresentado por 85 (24,1\%) das participantes foi o encaminhamento para o hospital. Vieram de casa para o hospital 297 participantes $(84,1 \%)$, e $307(87,0 \%)$ das participantes utilizaram carro para chegar ao hospital. Com relação à frequência de procura da UBS diante de alterações durante a gestação, 138 (39,1\%) das gestantes disseram que não procuram a UBS quando apresentam problemas.

Tabela 2. Atendimento da gestante na unidade de saúde

(Continua)

\begin{tabular}{lc}
\hline & N=353 (\%) \\
\hline $\begin{array}{l}\text { Antes de procurar o hospital } \\
\text { procurou a UBS }\end{array}$ & \\
Sim & $87(24,6 \%)$ \\
Não & $228(64,6 \%)$ \\
Particular & $38(10,8 \%)$ \\
\hline Profissional que atendeu a ges- & \\
tante na UBS & \\
\hline Medico & $65(18,4 \%)$ \\
Enfermeiro & $18(5,1 \%)$ \\
Medico/Enfermeiro & $4(1,1 \%)$ \\
Outro & $1(0,3 \%)$ \\
Ninguém atendeu & $1(0,3 \%)$ \\
Não se aplica & $264(74,8 \%)$ \\
\hline O atendimento foi resolutivo & \\
\hline Sim & $9(2,5 \%)$ \\
Não & $78(22,1 \%)$ \\
Não procurou a UBS/Particular & $266(75,4 \%)$ \\
\hline
\end{tabular}

Motivo que levou a procura do

hospital após atendimento na

UBS

Foi atendida mais piorou

$1(0,3 \%)$

Foi atendida e encaminhada ao

hospital

$85(24,1 \%)$

Não gostou do atendimento

$1(0,3 \%)$

Não se aplica

$266(75,4 \%)$

Procedência 
(Conclusão)

\begin{tabular}{lc}
\hline & $\mathbf{N}=\mathbf{3 5 3}(\%)$ \\
\hline Casa & $297(84,1 \%)$ \\
Trabalho & $35(9,9 \%)$ \\
UBS & $7(2,0 \%)$ \\
Consultório médico/exames & $5(1,4 \%)$ \\
Outros & $9(2,5 \%)$ \\
\hline Locomoção até o hospital & \\
\hline Carro & $307(87,0 \%)$ \\
Ônibus & $31(8,8 \%)$ \\
SAMU/Bombeiros & $9(2,5 \%)$ \\
Caminhando & $4(1,1 \%)$ \\
Outros & $2(0,6 \%)$ \\
\hline Com que frequência procura a & \\
UBS diante de alteraçôes & \\
\hline Sempre & $108(30,6 \%)$ \\
Às vezes & $94(26,6 \%)$ \\
Não procura a UBS & $138(39,1 \%)$ \\
Não teve problemas & $13(3,7 \%)$ \\
\hline
\end{tabular}

Fonte: Dados da pesquisa, 2017.

De acordo com a realização do acompanhamento pré-natal, 345 participantes $(97,7 \%)$ relataram realizar o pré-natal, o mês de início do pré-natal predominou o primeiro mês de gestação com 144 participantes (40,8\%), e a data da última consulta de pré-natal foi há menos de um mês relatado por 321 participantes $(90,9 \%)$.

As principais queixas apresentadas pelas participantes do estudo como motivo para procurar o centro obstétrico foi dor com 176 participantes (49,9\%), sendo 53 (15\%) participantes com contrações; 46 (13\%) participantes com sangramento; 45 (12,7\%) participantes com perda de líquido amniótico; 34 (9,6\%) participantes pressão alta e $32(9,1 \%)$ participantes relataram que estava na hora de ganhar. O tempo de início da queixa apresentada que predominou foi mais de 48 horas relatado por 140 participantes (39,7\%).

Tabela 3. Queixas das participantes do estudo

(Continua)

\begin{tabular}{lc}
\hline & $\mathbf{N}=\mathbf{3 5 3}(\%)$ \\
\hline Queixas & \\
Dor & $176(49,9 \%)$ \\
Contraçoes & $53(15,0 \%)$ \\
Sangramento & $46(13,0 \%)$ \\
\hline
\end{tabular}

(Conclusão)

\begin{tabular}{lc}
\hline & N=353 (\%) \\
\hline Perda de líquido amniótico & $45(12,7 \%)$ \\
Pressão alta & $34(9,6 \%)$ \\
Expectativa de parturir & $32(9,1 \%)$ \\
Acompanhamento & $13(3,7 \%)$ \\
Tontura & $11(3,1 \%)$ \\
Encaminhada pela UBS & $10(2,8 \%)$ \\
Ruptura de bolsa & $10(2,8 \%)$ \\
Bebe não mexe & $7(2,0 \%)$ \\
Infecção urinária & $7(2,0 \%)$ \\
Cardiotocografia & $6(1,7 \%)$ \\
Gripe & $6(1,7 \%)$ \\
Perda do tampão mucoso & $5(1,4 \%)$ \\
Cesárea marcada & $4(1,1 \%)$ \\
Feto morto & $3(0,8 \%)$ \\
Hiperglicemia & $2(0,6 \%)$ \\
Curetagem & $2(0,6 \%)$ \\
Hiperemese & $2(0,6 \%)$ \\
Outros & $14(4,0 \%)$ \\
\hline
\end{tabular}

Início da queixa

$\begin{array}{lc}<2 \text { horas } & 9(2,5 \%) \\ 2 \text { a } 6 \text { horas } & 56(15,9 \%) \\ 6 \text { a } 24 \text { horas } & 66(18,7 \%) \\ 24 \text { a } 48 \text { horas } & 82(23,2 \%) \\ >48 \text { horas } & 140(39,7 \%)\end{array}$

Fonte: Dados da pesquisa, 2017.

Relacionado à procura das gestantes ao centro obstétrico 41,6\% (147) relataram que não haviam procurado o hospital outras vezes durante a gestação, 20,4\% (72) procuraram o hospital uma vez e 20,4\% (72) procuraram o hospital três vezes ou mais durante a gestação, os motivos apresentados para procurar o centro obstétrico, 72 participantes $(20,4 \%)$ relataram o mesmo motivo da procura atual, e $44(12,5 \%)$ das participantes relataram ter procurado o hospital outras vezes durante a gestação por motivo de dor. 
Tabela 4. Frequência da procura pelo hospital e queixa das participantes do estudo

\begin{tabular}{ll}
\hline & $\mathbf{N}=353(\%)$ \\
\hline $\begin{array}{l}\text { Frequência da procura pelo hospital } \\
\text { durante a gestação }\end{array}$ \\
Nenhuma vez \\
1 vez & $147(41,6 \%)$ \\
2 vezes & $72(20,4 \%)$ \\
3 vezes ou mais & $62(17,6 \%)$ \\
\hline Queixas & $72(20,4 \%)$ \\
\hline Nenhuma queixa apresentada & \\
Mesma da procura atual & $146(41,4 \%)$ \\
Dor & $72(20,4 \%)$ \\
Sangramento & $44(12,5 \%)$ \\
Infecção urinária & $31(8,8 \%)$ \\
Acompanhamento & $15(4,2 \%)$ \\
Pressão alta & $9(2,5 \%)$ \\
Mal-estar & $6(1,7 \%)$ \\
Perda de líquido & $6(1,7 \%)$ \\
Cólica renal & $5(1,4 \%)$ \\
Queda & $5(1,4 \%)$ \\
Movimentos fetais ausentes & $4(1,1 \%)$ \\
Contração & $3(0,8 \%)$ \\
Crise de rinite & $2(0,6 \%)$ \\
Anemia & $2(0,6 \%)$ \\
Trombo flebite & $1(0,3 \%)$ \\
Acidente carro/moto & $1(0,3 \%)$ \\
& $1(0,3 \%)$ \\
& \\
\hline
\end{tabular}

Fonte: Dados da pesquisa, 2017.

\section{DISCUSSÃO}

DADOS SOCIODEMOGRÁFICOS DAS PARTICIPANTES DA PESQUISA

A faixa etária predominante das participantes do estudo foi de 21 a 30 anos de idade com 163 participantes (46,2\%), o município com mais participantes que procuraram o centro obstétrico durante a pesquisa foi Criciúma com 252 participantes $(71,4 \%)$, e em relação à escolari- dade a maioria, 136 (38,5\%), tinha o ensino médio completo. A ocupação que teve predominância foi do lar com 104 participantes $(29,5 \%)$.

No estudo de Oliveira et al., ${ }^{7}$ a maioria das gestantes (60\%) também apresentou idade maior de 20 anos. Assim como no estudo de Gaioso et al., ${ }^{8}$ em que a faixa etária predominante foi de mulheres com idade entre 21 e 30 anos (61,0\%), quanto ao grau de escolaridade, a maioria $(53,0 \%)$ possuía ensino médio completo, 53,5\% das mulheres não estavam ativas no mercado de trabalho, prevalecendo as que exerciam atividades no lar.

A escolaridade reflete as condições socioeconômicas da mulher e está associada ao baixo peso ao nascer, à perimortalidade, à neomortalidade e à mortalidade infantil, assim como ao aumento de partos e inadequação da assistência ao pré-natal? .

A idade avançada para a gravidez se apresenta como fator de maior risco

de desfechos maternos e perinatais adversos devido à gestação e complicações associadas e, portanto, precisam ser avaliadas ${ }^{10}$.

Gestação, parto e puerpério são períodos de transição na vida da mulher, marcados por expectativas, idealizações, incertezas e medos. As experiências pessoais vivenciadas nesses momentos são fortemente influenciadas pela cultura ${ }^{11}$.

Os fatores socioeconômicos estão ligados a diversos fatores que podem influenciar desde a idade gestacional em que as mulheres iniciam o pré-natal até seu estado nutricional, o que aumenta a responsabilidade de proporcionar maior qualidade da assistência individualizada voltada para a gestante nos serviços de saúde ${ }^{7}$.

\section{ATENDIMENTO DA GESTANTE NA UNIDADE DE SAÚDE}

De acordo com o atendimento da gestante na UBS, 228 (64,6\%) das participantes da pesquisa não procuraram a UBS antes de ir ao centro obstétrico. Sobre a resolução do atendimento sobre a perspectiva das gestantes que procuraram a UBS antes de ir ao hospital, 78 participantes $(22,1 \%)$ não consideraram o atendimento resolutivo. Com relação à frequência de procura da UBS diante de alterações durante a gestação, 138 (39,1\%) das gestantes disseram que não procuram a UBS quando apresentam problemas. 
Muitas gestantes alegam a falta de confiança no cuidado recebido como motivo para não realizarem o pré-natal na UBS. Esse quadro demonstra possíveis falhas no processo, que traz elementos importantes da atuação dos profissionais da Atenção Básica, especialmente o enfermeiro, principal profissional responsável pelo acompanhamento do pré-natal, já que o Ministério da Saúde recomenda o mínimo de seis consultas, sendo duas realizadas pelo médico e seis pelo enfermeiro ${ }^{12}$.

Grande importância deve ser atribuída à organização da UBS, de modo a facilitar a marcação das consultas médicas e dos exames, visto que, boa parte das mulheres recorre ao hospital/maternidade justamente pela facilidade do atendimento, considerando que há a marcação prévia das consultas e que os exames são realizados nesse local, conferindo, assim, maior conforto e comodidade às gestantes ${ }^{8}$.

"A satisfação dos usuários dos serviços de saúde é uma das medidas que mais apresentam resultado para avaliar a qualidade dos cuidados prestados"13:1. Há poucos trabalhos que avaliam a opinião das mulheres com a assistência recebida durante o processo gestacional. São poucos, também, os estudos que buscam explorar os fatores associados a essa avaliação do cuidado. Portanto, trabalhos que avaliam a satisfação do usuário contribuem para o enriquecimento do conhecimento na área ${ }^{14}$.

Assim, o Ministério da Saúde ressalta a importância desse acompanhamento e incentiva todas as gestantes a buscarem o atendimento gratuito no SUS, sendo a UBS a porta de entrada preferencial da gestante, ponto de atenção estratégico para melhor acolher suas necessidades, proporcionando um acompanhamento longitudinal e continuado, principalmente ${ }^{3}$.

\section{QUEIXAS PRINCIPAIS DAS PARTICIPANTES DA PESQUISA}

Nesta pesquisa, as principais queixas das participantes como motivo para procurar o centro obstétrico foram dor, contrações, sangramento, perda de líquido amniótico, pressão alta e expectativa de parturir, dentre outras como tontura, gripe, infecção urinária e perda do tampão mucoso. O tempo de início da queixa, também foi abordado e predominou mais de 48 horas relatado por 140 participantes $(39,7 \%)$.
No estudo de Rodrigues ${ }^{15: 87}$, a principal queixa das gestantes internadas no período também foi a dor pélvica ou lombar - 114 (71,7\%), seguida de perda de líquido amniótico 51 (32,1\%) e contrações uterinas 46 (28,9\%), hipertensão arterial 11 (6,9\%).

As alterações fisiológicas decorrentes do desenvolvimento fetal acabam por repercutir na postura da gestante, podendo ocasionar desconfortos corporais ao longo da gravidez. A dor lombar é a mais frequente entre as gestantes, ocasionando limitações físicas ${ }^{16}$.

No período gestacional ocorre o crescimento do volume do útero e das mamas, com consequente mudança do centro de gravidade da mulher. Em decorrência disso, podem acontecer algumas compensações posturais, como a hiperextensão de joelhos, a diminuição do arco plantar e a anteversão pélvica. Essas compensações posturais podem tensionar a musculatura paravertebral e causar lombalgia ${ }^{17}$.

A dor lombar é considerada um dos cinco sintomas mais habituais durante a gravidez, é encontrada em até $50 \%$ das mulheres grávidas e está presente até o final da gestação, principalmente a partir do terceiro trimestre, podendo estar relacionada às alterações posturais que se iniciam entre o terceiro e o nono mês da gestação ${ }^{18}$.

A presença de contrações uterinas rítmicas e regulares, porém sem modificação cervical, caracteriza-se o falso trabalho de parto prematuro. Tais casos costumam evoluir bem apenas com o repouso, principalmente se identificadas e tratadas a causa de base. Na eventualidade de as contrações persistirem, há necessidade de uso de tocolíticos e, portanto, a mulher deverá ser encaminhada para hospital de referência ${ }^{3}$.

Para o diagnóstico de trabalho de parto prematuro, deve-se considerar a contratilidade uterina e as modificações cervicais. É importante lembrar que, durante a gestação, existem contrações uterinas denominadas de Braxton-Hicks, que são diferentes daquelas do trabalho de parto, pela ausência de ritmo e regularidade ${ }^{3: 169}$.

Na presença de trabalho de parto prematuro com colo modificado, a mulher deve ser encaminhada para um hospital de referência. $\mathrm{O}$ trabalho de parto prematuro constitui situação de risco gestacional. Portanto, a pacien- 
te deve ser encaminhada para centro de referência ${ }^{3}$.

Entre 10 a $15 \%$ das gestações apresentam hemorragias. Estas hemorragias podem representar complicação gestacional ou agravos ginecológicos concomitantes com o período gravídico. As mais importantes situações hemorrágicas gestacionais na primeira metade da gestação são abortamento, gravidez ectópica, neoplasia trofoblástica gestacional benigna, descolamento corioamniótico, na segunda metade da gestação são placenta prévia, descolamento prematuro da placenta, rotura uterina ${ }^{19}$.

A rotura prematura das membranas ovulares é caracterizada pela rotura espontânea das membranas ovulares antes do início do trabalho de parto em qualquer idade gestacional. Rotulamos como período de latência o tempo decorrente entre a rotura das membranas e o início do trabalho de parto. Apresenta incidência entre $3 \%$ e $18,5 \%$. Aproximadamente $25 \%$ dos casos ocorrem antes do termo e acabam respondendo por cerca de $30 \%$ de todos os recém-nascidos prematuros ${ }^{3}$.

Está associada a um número considerável de complicações, que variam significativamente com a idade gestacional em que o quadro se instalou e a duração do período de latência. Há incremento de infecções maternas e perinatais, prematuridade, partos operatórios, deformações e amputações fetais e hipóxia ${ }^{3: 167}$.

Dentre os problemas específicos do período gestacional merece destaque a questão das doenças hipertensivas específicas da gestação, que tem sido discutido mundialmente, por ser uma das maiores causas de morte materna, tornando-se um problema de saúde pública ${ }^{20}$.

Hipertensão é a pressão arterial igual ou maior que 140/90 mmHg baseada na média de pelo menos duas medidas. A pressão arterial deve ser mensurada com a gestante sentada, com o braço no mesmo nível do coração e com um manguito de tamanho apropriado ${ }^{19}$.

As síndromes hipertensivas da gestação são classificadas em: Hipertensão crônica (Observada antes da gravidez, ou antes de 20 semanas de gestação, ou diagnosticada pela primeira vez durante a gravidez e não se resolve até 12 semanas após o parto). Pré-eclâmpsia/eclampsia - Hipertensão que ocorre após 20 sema- nas de gestação (ou antes, em casos de doença trofoblástica gestacional ou hidropsia fetal) acompanhada de proteinúria, com desaparecimento até 12 semanas pós-parto. $\mathrm{Na}$ ausência de proteinúria, a suspeita se fortalece quando o aumento da pressão aparece acompanhado por cefaleia, distúrbios visuais, dor abdominal, plaquetopenia e aumento de enzimas hepáticas. Hipertensão gestacional (sem proteinúria) Como a proteinúria pode aparecer tardiamente, o diagnóstico será retrospectivo, sendo necessário afastar pré-eclâmpsia. Deve-se seguir as condutas clínicas e obstétricas recomendadas para pré-eclâmpsia ${ }^{19: 46}$.

Nas gestações pré-termo, o controle ambulatorial pode ser iniciado após a hospitalização se confirmadas as condições materno-fetais estáveis, com as seguintes recomendações: consultas semanais, repouso relativo (evitar grandes esforços), pesar diariamente pela manhã, proteinúria na fita semanalmente pela manhã, medir a pressão arterial pelo menos uma vez ao dia ${ }^{19}$.

A ocorrência de Infecção do Trato Urinário é de grande dispersão no mundo e, especialmente na gravidez, pode implicar em enredos relevantes, estando associada à morbimortalidade materna e perinatal, gerando consequências para o binômio mãe-filho ${ }^{21}$.

Infecção comum em mulheres jovens, que representa a complicação clínica mais frequente na gestação, ocorrendo em $17 \%$ a $20 \%$ das mulheres nesse período. Está associada à rotura prematura de membranas, ao aborto, ao trabalho de parto prematuro, à corioamnionite, ao baixo peso ao nascer, à infecção neonatal, além de ser uma das principais causas de septicemia na gravidez. Cerca de $2 \%$ a $10 \%$ das gestantes apresentam bacteriúria assintomática, sendo que $25 \%$ a 35\% desenvolvem pielonefrite aguda ${ }^{3}$.

Em todos os casos de infecção urinária deve-se realizar cultura de urina para controle de cura sete dias após o final do tratamento e esta deve ser repetida mensalmente até o parto. Se o tratamento falhar ou a infecção recorrer, tratar com antibiótico apropriado para o microrganismo de acordo com a cultura e testes de sensibilida$\mathrm{de}^{19}$. 
FREQUÊNCIA DA PROCURA DO HOSPITAL E QUEIXAS DAS GESTANTES

Relacionado à procura das gestantes ao centro obstétrico 41,6\% (147) relataram que não haviam procurado o hospital outras vezes durante a gestação, 20,4\% (72) procuraram o hospital uma vez, e 20,4\% (72) procuraram o hospital três vezes ou mais durante a gestação; os motivos apresentados para procurar o centro obstétrico, 72 participantes $(20,4 \%)$ relataram o mesmo motivo da procura atual, e $44(12,5 \%)$ das participantes relataram ter procurado o hospital outras vezes durante a gestação por motivo de dor.

As gestantes que fizeram pré-natal nas UBS alegam que encontraram problemas como dificuldade para agendamento das consultas com o profissional médico e longo tempo de espera para realização de exames laboratoriais. Embora a UBS seja o local adequado para a realização desse atendimento, há insegurança quanto ao cuidado recebido ${ }^{8}$.

Nesse sentido, as mulheres procuram os hospitais/maternidade, as consultas são realizadas com médicos especializados. Portanto, um relacionamento de confiança entre os profissionais, a gestante e sua família é determinante na melhoria dos serviços em saúde e na adesão precoce ao pré-natal ${ }^{22}$.

\section{CONCLUSÃO}

O objetivo geral da pesquisa foi alcançado, e diante da realização dos objetivos específicos e análise de resultados ficou claro uma fragilidade na comunicação entre os serviços de saúde, evidenciado pelo relato das participantes. Foi possível perceber a insegurança e o medo das gestantes diante do problema pelo qual estavam passando, sem saber quem procurar para lhe ajudar, e no momento da dúvida, o lugar que elas enxergavam confiança era o centro obstétrico.

Pensando nisso, sugerimos que os gestores aumentem o incentivo aos programas de integração interinstitucionais e de educação permanente em saúde, objetivando a otimização dos profissionais de saúde, tanto da atenção primária como secundária, e o empoderamento das mulheres, usuárias do serviço público, para prevenção dos agravos evitáveis da gestação. A atuação da enfermagem é de suma importância nesse processo, o enfermeiro (a) deve estar capacitado para orientar as mulheres e proporcionar uma gestação saudável e segura por meio de inúmeras ações e intervenções. Durante a realização do projeto foram encontradas algumas dificuldades, como a paralisação do local da realização do estudo, que interferiu diretamente na amostra e motivo da procura, pois estava restrito somente ao atendimento de urgência e emergência obstétricas.

\section{REFERÊNCIAS}

1. Ministério da Saúde (BR). Secretaria de Atenção à Saúde Gravidez, parto e nascimento com saúde, qualidade de vida e bem-estar. Brasília, DF: Ministério da Saúde; 2013.

2. Veras TCS, Mathias TAF. Hospitalizations leading causes for maternal disorders. Rev. esc. enferm. USP, São Paulo. 2014; 48(3):401-8.

3. Ministério da Saúde (BR). Secretaria de Atenção à Saúde. Departamento de Atenção Básica. Atenção ao pré-natal de baixo risco. Brasília, DF: Ministério da Saúde; 2012.

4. Oliveira DC, Mandú ENT. Mulheres com gravidez de maior risco: vivências e percepções de necessidades e cuidado. Esc. Anna Nery, Rio de Janeiro. 2015;19(1):93-101.

5. CEP/HSJ. Dados cedidos pelo Comitê de Ética em Pesquisa do Hospital São José. Criciúma, SC; 2016.

6. Brasil. Conselho Nacional de Saúde. Resolução nº 510, de 07 de abril de 2016. Brasília, DF, 2016. Disponível em:<http:/conselho.saude.gov.br/ resoluções /2016 /Reso510.pdf. Acesso em: 12 dez. 2016.

7. Oliveira EKS, Alves JCC, Cavalcante AL, Santos LGML, Miyazawa AP, Moura MRW, et al. Perfil das gestantes cadastradas em um centro de referência da assistência social do município de Rio Largo no estado 
de Alagoas no período de 2013 a 2014. Cad. Grad. Ciênc. Biológ. Saúde. 2016;3(2):177-90.

8. Gaioso EMS, Santos FCS, Ferreira AGN, Santos LH, Santos Neto M, Santos FS. Gestantes atendidas em hospital de referência do SUS: quem são e quais os motivos. J Manag Prim Health Care. 2014;5(1):33-9.

9. Teixeira SVB, Rocha CR, Moraes DSD, Marques DM, Villa ASE. Educação em saúde: a influência do perfil sócio-econômico-cultural das gestantes. Rev enferm UFPE online. 2010;4(1):133-41.

10. Ojule JD, Ibe VC, Fiebai PO. Pregnancy outcome in elderly primigravidae. Ann Afr Med. 2011;10:204-8.

11. Castro MR, et al. Gestantes que participam da organização não governamental bem nascer: estudo descritivo. R. Enferm. Cent. O. Min. 2013; 3(3):851-62.

12. Ministério da Saúde (BR). Atenção à gestante e à puérpera no SUS-SP: manual técnico do pré-natal e puerpério. São Paulo: SES/SP; 2010.

13. Sawyer A, Ayers S, Gyte G, Rabe H, Duley L. Measures of satisfaction with care during labour and birth: a comparative review. Bmc Pregnancy Childbirth. 2013;13(1):1-10.

14. Baldisserotto ML. Associação entre as boas práticas de assistência ao trabalho de parto e parto e a avaliação pelas puérperas do cuidado recebido. [Dissertação mestrado]. Rio de Janerio: Escola Nacional de Saúde Pública Sergio Arouca (ENSP/Fiocruz); 2015.

15. Rodrigues ET. Perfil epidemiológico das gestantes de alto risco internadas em um hospital de Cáceres - Mato Grosso. [Dissertação]. Brasília: Universidade de Brasília; 2010.

16. Silva YF. Avaliação postural através da biofotogrametria em gestantes com dor lombar. [trabalho de conclusão de curso]. Paraíba: Universidade Estadual da Paraíba; 2013.
17. Gomes MRA, Araújo RC, Lima AS, Pitangui ACR. Lombalgia gestacional: prevalência e características clínicas em um grupo de gestantes. Rev Dor. 2013;14(2):114-7.

18. Souza PS. Os benefícios da fisioterapia nas alterações posturais em grávidas do $3^{\circ}$ ao $9^{\circ}$ mês. [Dissertação]. Goiânia: Faculdade de Ávila; 2007.

19. Ministério da Saúde (BR). Secretaria de Atenção à Saúde. Departamento de Ações Programáticas Estratégicas. Manual Técnico, Gestação de Alto Risco. Brasília, DF: Ministério da Saúde; 2012.

20. Nery IS, Viana LS, Viana LMM, Araújo TME, Feitosa VC, Pereira VF. Perfil epidemiológico e obstétrico de gestantes com Síndrome Hellp. Cogitare Enferm. 2014;19(1):147-52.

21. Santos KAG, Ribeiro JLS, Silva PO. Infecção do trato urinário em gestantes. Anais da Jornada Científica; outubro 2016; Faculdade de São Lourenço. São Lourenço, MG; 2016.

22. Passos AA, Moura ERF. Indicadores de processo do Programa de Humanização no pré-natal e nascimento no Ceará, Brasil: análise da série histórica 20012006. Cad. Saúde Pública. 2008; 24(7):1570-80.

Recebido em: 04/07/2017 Aceito em: 22/02/2018 